ESPAÇO TEMATICO - SERVIÇO SOCIAL: FORMAÇÃO, TRABALHO POFISSIONAL E

TENDÊNCIAS TEÓRICAS CONTEMPORÂNEAS

\title{
Serviço social e pesquisa científica: uma relação vital para a formação profissional
}

\author{
Luciene Araújo ${ }^{1}$ \\ https://orcid.org/0000-0002-1509-8587 \\ Gilcélia Batista de Góis ${ }^{2}$ \\ https://orcid.org/0000-0002-6535-6089
}

\author{
Gleidiane Almeida de Freitas ${ }^{3}$ \\ https://orcid.org/0000-0001-9996-5176
}

\author{
Mariana Gleicy de Oliveira Silva Sousa ${ }^{4}$ \\ https://orcid.org/0000-0002-3397-0754
}

\begin{abstract}
${ }^{1}$ Universidade do Estado do Rio Grande do Norte, Faculdade de Serviço Social, Programa de Pós-Graduação em Serviço Social e Direitos Sociais, Mossoró, RN, Brasil

${ }^{2}$ Universidade do Estado do Rio Grande do Norte, Faculdade de Serviço Social, Programa de Pós-Graduação em Serviço Social e Direitos Sociais, Mossoró, RN, Brasil

${ }^{3}$ Universidade do Estado do Rio Grande do Norte, Faculdade de Serviço Social, Mossoró, RN, Brasil

${ }^{4}$ Universidade do Estado do Rio Grande do Norte, Faculdade de Serviço Social, Mossoró, RN, Brasil
\end{abstract}

\section{Serviço social e pesquisa científica: uma relação vital para a formação profissional}

Resumo: A formação profissional em Serviço Social demanda a interação com inúmeros fatores da vida cotidiana, sendo a pesquisa científica um dos meios adotados para conhecê-los. Partindo desse pressuposto, objetivamos problematizar o lugar da pesquisa científica em nossa formação profissional, bem como apontar alguns desafios inerentes à esta atividade teórico-prática evidenciando a sua importância no processo de ensino-aprendizagem. A discussão está estruturada em uma breve introdução; depois trataremos sobre o sentido da pesquisa científica; em seguida problematizaremos a importância desta na formação profissional em Serviço Social; por fim, apontaremos algumas reflexões sobre a temática em tela. Fundamentando-se em uma revisão de literatura, sob a luz da teoria social crítica, consideramos que a dimensão investigativa em meio às contradições do sistema econômico e o culto aos estigmas sociais e culturais, é de ímpar relevância para uma profissão comprometida com a ruptura de análises discriminatórias e a construção de uma sociedade humanamente emancipada.

Palavras-chave: Serviço Social. Formação profissional. Pesquisa científica.

\section{Social Work and Scientific Research: A Vital Relationship for Professional Education}

Abstract: Professional education in social work entails interaction with many factors of daily life, and scientific research is a way to learn about these factors. Based on this assumption, this study discusses the position of theoretical and practical scientific research regarding professional education, presenting its inherent challenges and highlighting its importance in the teaching-learning process. The discussion is organized in a brief introduction, followed by a debate on the meaning of scientific research. The article reflects on the importance of scientific research in the professional education of social workers and provides final considerations and reflections. Supported by a literature review and guided by the critical social theory, the study recognizes the relevance of the investigative dimension amidst the contradictions of the economic system and the cult of social and cultural stigmas. This dimension is crucial to developing a profession committed to the rupture of discriminatory analyzes and the construction of a humanly emancipated society. Keywords: Social Work. Professional education. Scientific research.

Recebido em. 30.06.2019. Aprovado em 17.09.2019. Revisado em 13.11.2019.

(C) O(s) Autor(es). 2020 Acesso Aberto Esta obra está licenciada sob os termos da Licença Creative Commons Atribuição-NãoComercial 4.0 Internacional (https://creativecommons.org/licenses/by-nc/4.0/deed.pt_BR), que permite copiar, distribuir e reproduzir em qualquer meio, bem como adaptar, transformar e criar a partir deste material, desde que para fins não comerciais e que você forneça o devido crédito aos autores e a fonte, insira um link para a Licença Creative Commons e indique se mudanças foram feitas. 


\section{Introdução}

É inegável a importância da pesquisa tanto para o âmbito acadêmico - considerado lugar privilegiado para a realização da mesma ", como para a sociedade de maneira geral, pois contribui para o avanço do conhecimento e o desvendamento da realidade social. É uma ação e não pode circunscrever a espaços ou quadrantes em que um grupo de pessoas se volta para determinadas temáticas que são, essencialmente, de interesse pessoal, enquanto que problemas, fenômenos e complexos sociais nos rodeiam cotidianamente e se avolumam.

Comumente escutamos falar sobre pesquisa, seja pesquisa de preço, pesquisa de opinião, pesquisa para delinear perfil de determinados segmentos e consumidoras(es). No entanto, quando paramos para refletir sobre pesquisa, numa perspectiva de totalidade crítica, estamos nos referindo à pesquisa acadêmica. Isto não quer dizer que outros espaços e instituições não realizem pesquisas neste viés. Não queremos dizer que as demais pesquisas não sejam importantes, ao contrário, cada uma tem sua relevância, visto dessa forma, estamos nos propondo a fazer um recorte para a importância da pesquisa na formação profissional das(os) assistentes sociais.

A citada profissão, de natureza investigativa e interventiva, para dar respostas qualificadas às(aos) usuárias(os), precisa conhecer o cotidiano, bem como o contexto na qual se encontra. Dessa maneira, pensar o Serviço Social sem a produção do conhecimento no qual é fundamentado, criado e recriado nas pesquisas realizadas é uma ideia inconcebível.

A profissão, para a desmistificação da realidade e desnaturalização dos estigmas sociais e culturais, através da pesquisa social, se utiliza da teoria social crítica que visa à superação da dicotomia teoria-prática e nega a apropriação do imediato como sendo a essência da realidade.

Na prática profissional, a pesquisa possibilita que as(os) assistentes sociais saiam do senso comum, do que está aparente no cotidiano e tenham uma noção dos nexos sociais que envolvem a vida das(os) usuárias(os)a. No âmbito acadêmico, o conhecimento produzido e construído coletivamente contribui para a aproximação e compreensão das expressões da Questão Social, possibilitando o pensar em estratégias para a redução das desigualdades e para a transformação social.

À vista do exposto, nosso objetivo é delinear algumas reflexões sobre a relevância da pesquisa científica para a formação profissional em Serviço Social, bem como problematizar o seus desafios e problemáticas na contemporaneidade, partindo da compreensão de que a pesquisa no âmbito das relações da citada profissão não está voltada apenas para a descrição ou reflexão em si do mundo real, mas se constitui uma atividade transformadora.

Para isso, o referido estudo apresentará abordagem qualitativa e se utilizará da revisão de literatura. Adotamos a perspectiva teórica materialista histórica dialética para nortear nossas discussões alicerçadas no entendimento de que as sociedades humanas existem num determinado espaço, num determinado tempo, em que os grupos sociais as constituem mutáveis e que tudo - instituições, leis, visões de mundo "é provisório, passageiro e está em constante dinamismo e, potencialmente, pode ser transformado.

Dessa maneira, o trabalho está estruturado da seguinte forma: na primeira parte debateremos a pesquisa científica de maneira geral, sua contribuição social, seu conceito e algumas polêmicas que a envolvem; em seguida, discutiremos a relação da pesquisa científica com o Serviço Social; depois sinalizaremos a pesquisa científica feita por assistentes sociais como ferramenta para uma intervenção qualificada diante do desafio de pesquisar para transformar a realidade social. E, por fim, faremos inferências sobre os limites e desafios postos para a pesquisa no Serviço Social.

\section{Pesquisa científica: breves considerações}

Etimologicamente pesquisa significa: busca do conhecimento utilizando determinados recursos e instrumentos científicos. É aquilo que utiliza rigor, objetividade. Para Demo (1987, p. 22), "a atividade básica da ciência é a pesquisa", pois é o ponto de partida para a construção do conhecimento, visto que não existe ciência sem pesquisa. Segundo o mesmo autor, "pesquisa é a atividade científica pela qual descobrimos a realidade (Idem, p. 23)". Visto que para a ciência não existe conhecimento acabado, há sempre algo novo a se desvendar nas mais variadas realidades sociais em que estas estão em constante transformação.

É consenso entre autoras(es) que há inúmeras formas de produção de conhecimentos ou construção do saber, como a tradição, a religião, a ciência por exemplo (LAVILLE; DIONE, 1999). Aqui destacamos a produção de conhecimentos advinda da ciência com sua sistematização do conhecimento, seu rigor, objetividade, com seu compromisso em responder os problemas da sociedade. Fazer ciência é, constantemente, uma busca pelo aperfeiçoamento do conhecimento, em que o mesmo pode ser refutado ou aprimorado. 
Desse modo, é um equívoco afirmar que toda coleta de dados é uma pesquisa, pois ela é também um artesanato intelectual que requer esforços substanciais do(a) pesquisador(a), saber manusear técnicas, instrumentais, métodos e base teórica para interpretação dos dados. Em tese, a pesquisa é de fato algo refinado, precisa ter script. A aleatoriedade não fará parte de uma pesquisa, pois esta demanda uma funcionalidade, originalidade, relevância, metodologia, dentre outros elementos.

Posto isto, a pesquisa, seja ela bibliográfica, documental ou de campo, possibilita descobertas sobre uma determinada realidade a qual se propõe problematizar. Ao pesquisarmos ampliamos nosso olhar crítico, comprovamos, ou não, nossas teses, afinal, a arte de pesquisar exige fundamentação teórica, para embasar e dar credibilidade à discussão abordada, e de um método de análise que respalde o caminho percorrido para chegarmos à solução do cotidiano problematizado.

Além disso, é imperioso problematizar a relação do sujeito com o objeto de pesquisa - aqui destacamos as ciências sociais "e chamar a atenção para cuidados importantes antes, durante e após o desenvolvimento da pesquisa (REIS, 2015). Logo, é pertinente que saíamos parcialmente da abstração dos livros, dos textos, revistas científicas e passemos para o outro lado, mas que não é desarticulado: o empírico.

Posto isto, empírico no mundo acadêmico significa: descrição de observações ou pesquisas baseadas em observações concretas. Para Johnson (1997, p. 83), "distingue-se, portanto, de algo baseado apenas em processos mentais, teóricos ou de qualquer outro tipo [...]. Empirismo é um método filosófico baseado na idéia de que a única forma válida de conhecimento é aquela obtida através dos sentidos".

Partindo dessas assertivas, entendemos que a pesquisa científica possibilita às(aos) discentes e docentes sair da dimensão teórica (imprescindível) e ir para o mundo concreto, isto é, ampliar o olhar sob diversos fenômenos sociais que rodeiam e requerem respostas concretas e palpáveis, mas sem cair na redução do empirismo.

Sobre a questão, Freire (1975 apud FAZENDA, 2008) afirma que admirar a realidade significa objetivála, apreendê-la como campo de sua ação (prática, fazer profissional) e reflexão. Significa penetrá-la cada vez mais no objeto definido para descobrir as interrelações verdadeiras dos fatos percebidos. Isto, a nosso ver, é pensar uma dialética do conhecimento que, para Freire (1975), é a própria práxis: reflexão-ação, reflexões sobre a ação-nova ação.

Segundo Godoy (1995), na atualidade a pesquisa ocupa um reconhecido lugar entre as várias possibilidades de se estudar fenômenos que envolvam seres humanos e suas intrínsecas relações sociais estabelecidas em diversos ambientes, seja na dimensão quantitativa ou qualitativa.

Por conseguinte, é pertinente entendermos - ou captar os fenômenos " a partir da perspectiva das pessoas, considerando todos os pontos de vistas envolvidos e relevantes neste aspecto. Sumariamente, o que importa não é como os dados foram coletados, mas como serão analisados procurando entender a dinâmica do processo. Aqui destacamos o papel do(a) pesquisador(a), que

[...] de maneira explícita ou não é possível verificar o comprometimento do pesquisador com um determinado projeto de sociedade seja através da adoção de uma perspectiva que almeja mudanças estruturais na sociedade ou através de posturas que contribuam para a manutenção do status quo (REIS, 2015, p. 154).

Pensando assim, observa-se que não existe pesquisa mais importante que outra. $\mathrm{O}$ essencial é compreender qual a perspectiva de análise do(a) pesquisador(a), qual sua base teórico-metodológica para tratar o objeto em estudo. Vale ressaltar que a neutralidade não passa de um mito, tendo em vista que influenciamos e somos influenciadas(os) pelos nossos objetos de estudos. Corroboramos, pois, com Laville e Dione (1999, p. 33) quando afirmam que:

Se, em ciências humanas, os fatos dificilmente podem ser considerados como coisas, uma vez que os objetos de estudo pensam, agem e reagem, que são atores podendo orientar a situação de diversas maneiras, é igualmente o caso do pesquisador: ele também é um ator agindo e exercendo sua influência.

Logo, pesquisa é uma construção coletiva e embebida de intencionalidade. "Nesse sentido, Gustin e Dias (2006, p. 35) alertam que "não é possível descrever o objeto de forma neutra [...], pois eles são construídos contextualmente" (REIS, 2015, p. 159), uma vez que até mesmo a técnica a ser utilizada é um produto humano, e não algo que se encontra naturalmente. Dessa forma, quando um(a) pesquisador(a) escolhe determinada técnica ele(a) demonstra quais são seus interesses e sua visão de mundo. Por conseguinte, precisamos pensar pesquisas que respondam/atendam os anseios daqueles(as) que durante décadas ficam à margem ou são meramente pesquisados(as) e/ou entrevistados(as).

Dito isso, é necessário ouvir os sujeitos não apenas para obter informações, mas para saber sua opinião sobre a pesquisa. Dar voz e vez não apenas para conferir visibilidade, mas para melhor encaminhar 
a pesquisa a fim de obter solução para o problema estudado. O sujeito da pesquisa é a parte mais frágil desta relação. Toda e qualquer consequência advinda do resultado de uma pesquisa irá recair sob o universo populacional estudado.

À vista do exposto, "faz-se necessária, em especial no campo das ciências sociais, uma abordagem dialética da pesquisa, que se proponha inclusive a tratar o objeto não como algo inerte, mas que permita a esse participar ativamente da construção da pesquisa" (REIS, 2015, p. 164). E é sob esta perspectiva que as entidades representativas do Serviço Social irão delinear um projeto pedagógico ${ }^{1}$ ancorado na importância da pesquisa no processo de ensino-aprendizagem das(os) futuras(os) assistentes sociais, considerando-a basilar para a compreensão das expressões da Questão Social, para a avaliação dos resultados das políticas sociais públicas, para o fortalecimento da dimensão investigativa da profissão aliada às reflexões teóricas para a superação da dicotomia existente entre teoria e prática, "o que supõe uma formação profissional que imprima um perfil crítico, fundado em rigorosa capacidade teórica, ético-política e técnico-prática voltada ao conhecimento e transformação da realidade" (KOIKE, 2009, p. 249).

Isto posto, diante à demanda de conhecer a realidade concreta para apreender como se manifesta os elementos constitutivos da ordem sociometabólica do capital, "[...] a formação deve estar a serviço da produção do conhecimento que tenha relevância para as lutas sociais e se dirija à emancipação dos trabalhadores, [destarte] o lugar da pesquisa está bem definido e resguardado". (GUERRA; BACKX; REPETTI, 2013, p. 230).

\section{Pesquisa científica e Serviço Social}

A pesquisa científica e o Serviço Social se entrelaçam e se alimentam. Para tratar desta relação citamos Pereira (2005, p. 18), por compreender a sua vivência e experiência com a pesquisa no âmbito do Serviço Social:

A principal contribuição da pesquisa para o serviço social seria propiciar a construção de tipologias, de diagnósticos e tratamento mediante a conversão do conhecimento das ciências sociais em princípios para o exercício da prática profissional. Portanto, no ponto, o serviço social diferentemente das ciências, não estaria voltado para a acurada descrição e interpretação do mundo social, mas para o controle desse mundo, mediante o manejo de técnicas, informadas por disciplinas, tal como procedem ao seu ver, as tecnologias e as engenharias.

Dessa maneira, podemos compreender que a pesquisa no âmbito das relações do Serviço Social não está voltada apenas para a descrição ou reflexão em si do mundo real, mas se constitui uma atividade transformadora, a qual tem o objetivo de construir os diversos conhecimentos sobre as múltiplas expressões da Questão Social por meio da aproximação, explicação e apreensão dos aspectos sociais, econômicos, políticos e cultuais da realidade social, buscando encontrar respostas diante os desafios que são postos para a sociedade em geral.

De acordo com Ferreira et al. (2009), ao objetivarmos romper com a visão e compreensão conservadora e tecnicista se faz necessário, antes de qualquer decisão, termos uma formação sólida e crítica pautada nas Diretrizes Curriculares Nacionais para o Curso de Serviço Social que apresentam a pesquisa como algo fundamental no processo de formação, seja na graduação ou seja na pós-graduação.

Sobre essa discussão, Setubal (2007) demonstra certa preocupação com os cursos de Serviço Social acerca da elevada quantidade de disciplinas de pesquisa social sem o verdadeiro comprometimento com a essência do saber crítico, ocorrendo muitas vezes no âmbito acadêmico a fragilização do ensino pela falta de articulação com as demais disciplinas ou conteúdos abordados no decorrer da grade curricular, o que acaba penalizando o desenvolvimento da construção do conhecimento teórico e metodológico do ser social na formação acadêmica e, principalmente, refletindo negativamente na prática profissional dos(as) assistentes sociais.

Nesse sentido, Ferreira et al. (2009, p. 03), destaca a relevância da pesquisa como atividade fundamental dos(as) assistentes sociais para a realização da investigação e de intervenção da realidade social por meio de correntes teóricas:

A própria realidade tem suas particularidades, e torna-se complexa para os estudiosos, no entanto para melhor entender e compreender utilizamos de várias teorias, como o marxismo, fenomenologia e o positivismo e, de conceitos para a abordagem da realidade, como afirma Iamamoto (2007), os processos sociais e a pesquisa da realidade social são indissociáveis ao exercício profissional.

Dessa maneira, a dimensão da pesquisa assume um papel de extrema importância para a intervenção do exercício profissional, na qual se faz necessário utilizar os referenciais teóricos para abordagem e compreen- 
são da realidade social investigada. Ainda segundo a interpretação dos autores supracitados, é necessário destacar a liberdade no interior do Serviço Social, no tocante à utilização das correntes teóricas, o qual pode ser conceituado como pluralismo de ideias, porém se concentrando o aprimoramento em uma teoria; o que não pode ocorrer é a utilização de várias expressões teóricas com a finalidade de confundir a sua fundamentação caindo no poço chamado ecletismo.

Assim, o processo investigativo no Serviço Social se utiliza de aproximações, indagações, reflexões e apreensão de conhecimentos, a partir da capacidade teleológica do (agir e pensar) abordado pela corrente teórica marxista. O referencial teórico de Karl Marx estabelece uma dimensão ampliada de pesquisa que vai além da aparência dos fatos e estabelece relações no âmbito singular, particular e da totalidade, o que ocorre de forma dialética com a própria construção histórica da humanidade, contendo suas contradições e conflitos com o modo de produção.

No Serviço Social, o método materialismo histórico e dialético trilha o caminho investigativo na busca pela essência das coisas, a qual pode ser chamada de práxis transformadora, com o horizonte apontado para a transformação da ordem societária vigente. (BAPTISTA 2006; SETUBAL, 2007). Após estes breves apontamentos sigamos a discussão sobre o lugar e a importância da pesquisa na formação profissional em Serviço Social.

\section{Pesquisar para transformar: eis o desafio para o Serviço Social}

Quando nos remetemos ao Serviço Social x pesquisa $x$ transformação vem à nossa mente e ao ver de diversos(as) profissionais, estudantes e pesquisadores(as) uma velha inquietação: Serviço Social é ciência? Pesquisa? Talvez, ou certamente, estas questões vem à cena por entender que o Serviço Social tem, a priori e desde seu surgimento, a dimensão interventiva, no entanto com uma prática desvinculada de um referencial teórico crítico. Isso explica, em parte, certas inquietações.

De fato, somos uma profissão que exerce sua prática cotidianamente e pesquisa objetivando dar respostas às diversas expressões da Questão Social: pesquisa e produz conhecimentos. Atualmente, no cenário brasileiro temos inúmeros grupos de pesquisa registrados na Plataforma Sucupira, diversos cursos de pósgraduação lato sensu e stricto sensu, sem esquecer os centros de pesquisas existentes.

Por esta razão é impossível pensar o Serviço Social sem a produção do conhecimento o qual é fundamentado nas pesquisas realizadas. A afirmativa que fizemos anteriormente de pesquisar para transformar, tem como objetivo apresentar a pesquisa que transforma pelo simples fato de que quando temos dados teóricos e empíricos em nossas mãos devemos decifrá-los para responder a um determinado problema de pesquisa, seja nas ciências sociais ou nas ciências ditas exatas.

Sendo assim, podemos, coletivamente, transformar determinada realidade com a pesquisa que realizamos sobre tal. A título de exemplo, podemos mencionar que os médicos pesquisadores nos seus respectivos laboratórios podem encontrar alternativas e resoluções de determinadas doenças por meio de pesquisa. $\mathrm{O}$ Alzheimer é um exemplo vivo e atual, um grupo de pesquisadores conseguiu através de pesquisa encontrar alternativas para a doença citada.

Da mesma forma nós profissionais do Serviço Social. Ao nos debruçarmos sobre a realidade de um equipamento social (por exemplo, do Centro de Referência de Assistência Social - CRAS), realizamos diagnóstico, pesquisas, levantamentos de dados, conversarmos com as (os) usuárias (os) e a partir daí teremos uma possibilidade de apreensão daquela realidade.

Ora, a pesquisa é um contributo para uma profissão de natureza investigativa e interventiva, comprometida com uma atuação qualificada alicerçada na apreensão da realidade posta com suas multifacetadas expressões da Questão Social com as diversas determinações de raça, etnia, gênero, religião, idade dentre outras. Dito isso, Moraes, Juncá e Santos (2010, p. 435) afirmam que:

[...] a atitude investigativa é uma dimensão inseparável do processo de formação profissional e do cotidiano do Serviço Social, e que não se trata apenas de avançar no campo do conhecimento. É fundamental garantir a unidade entre o saber, o fazer, o saber fazer e o refazer, ancorados em uma clara compreensão do tipo de sociedade que queremos construir.

A investigação no âmbito do Serviço Social possibilita uma abertura do espaço para construir e reconstruir conhecimentos, como também questionar a verdade que se diz absoluta, o que está associada às ideologias, as pré-noções, visões de mundo e o senso comum.

Segundo Moraes (2013), a partir das últimas diretrizes gerais para o curso de Serviço Social o tema pesquisa e intervenção ficou conhecido na profissão, pois esse tema se tornou condição e princípio fundamen- 
tal da formação profissional. A pesquisa no âmbito da formação profissional possibilita realizar a relação entre a teoria e a prática, em que ambas são indissociáveis no âmbito acadêmico e na atuação profissional. A concepção de pesquisa viabiliza a ampliação da consciência crítica e política para desvendar os fatos, fenômenos sociais, bem como a dinâmica e as contradições da sociedade de classes.

Desse modo, é necessário discutir sobre os limites e desafios que são colocados para o Serviço Social, os quais inviabilizam " mas não impedem a prática investigativa de subsidiar estratégias de maneira crítica ao enfrentamento das multifacetadas expressões da questão social e ao contexto regressivo e neoliberal que estamos vivenciando na contemporaneidade.

A dimensão da pesquisa no Serviço Social é imprescindível na atividade profissional, em que assistentes sociais têm a capacidade de atuar e intervir nas variadas faces da questão social, desvendando a maneira com que o aparato estatal responde ou intervém sobre essas expressões e dando respostas às (aos) suas (seus) usuárias (os).

Acerca dos desafios da pesquisa, Setubal (2007) faz uma crítica em relação ao modelo produtivista no âmbito do Serviço Social, no tocante à elaboração aligeirada de produções e publicações na esfera da pesquisa sem a devida reflexão e contribuição para a categoria e a sociedade em geral. Segundo o autor, esse elevado número de publicações ocorre na maioria das vezes no campo da docência (stricto sensu), o qual acaba utilizando a pesquisa para ganhar titulação sem se preocupar com o aprofundamento do saber e a sua vinculação com o projeto ético político da profissão.

Ainda na interpretação de Setubal (2007), é necessário superar essas práticas desvinculadas do projeto profissional, como também a ação descomprometida com o conhecimento crítico e dialético, a qual a pesquisa não tem a finalidade de "cumprir exigências" do mercado ou da instituição de ensino, mas para formar alternativas que possibilitem a garantia e defesa dos direitos, sendo vinculada na perspectiva transformadora.

Entretanto, não podemos deixar de mencionar o avanço da dimensão investigativa de maneira comprometida, assim podemos abordar pontos positivos para a socialização da produção de conhecimentos nos meios de publicações (revista, jornais ou encontros) que tem contribuído e alcançando o amadurecimento intelectual do saber para a formação acadêmica e profissional.

Outro desafio que tem dificultado a ampliação da prática de pesquisa no âmbito das Instituições de Ensino Superior (IES), se refere ao avanço e pulverização dos cursos a distância " o Ensino a Distância (EAD). Segundo Ferrarez (2016), essa modalidade de ensino vem crescendo de maneira exorbitante no cenário brasileiro, particularmente na esfera privada, o qual está contribuindo para ampliação e legitimação do capital financeiro estrangeiro.

Os cursos ofertados nesta modalidade se configuram uma afronta às diretrizes curriculares, principalmente na ausência da prática da pesquisa, extensão e estágio sem garantia de supervisão acadêmica, o que tem penalizado os(as) discentes ao não terem estes um ensino de qualidade, como também vem acontecendo com a fragmentação nas condições de trabalho das(os) docentes. Ademais, de acordo com Silva, Matias e Nóbrega (2018, p. 113), "o aligeiramento da formação profissional afasta a ideia de universidade autônoma, com implicações para a pesquisa e para o conhecimento da realidade, a fim de atender a lógica mercantil [...]".

Nesse sentido, Iamamoto (2007) explicita a concepção de que o ensino universitário tem se estreitado com o mundo empresarial, em que o conhecimento se torna movido de interesses, ou seja, o saber é convertido em uma mercadoria a ser vendida para obtenção da lucratividade. Desse modo, a qualidade do ensino, pesquisa e extensão no meio universitário fica totalmente comprometida, formando assim sujeitos operacionais sem a capacidade de cultivar a razão crítica do saber para ir além dos muros da universidade.

A ampliação do EaD no âmbito do ensino universitário compromete a direção do projeto ético-político diante o empobrecimento do processo de ensino-aprendizagem, calcando trilhas para o resgate das raízes conservadoras inerentes a gênese da profissão. Desta feita, cursos aligeirados, minimalistas e desarticulados da proposta de uma formação profissional que sintonize, no mesmo patamar de relevância, as dimensões teórico-metodológica, ético-política e técnico-operativa, fomenta a despolitização da categoria profissional tendo em vista a fragmentação de experiências estudantis no meio acadêmico que poderiam contribuir pra a politização do exercício profissional (IAMAMOTO, 2007).

Em relação ao receituário neoliberal, Silva, Matias e Nóbrega (2018) abordam a questão do ataque a dimensão investigativa (pesquisa) em que as universidades têm sofrido arduamente com os grandes cortes orçamentários nos cursos de graduação e da pós-graduação.

$\mathrm{Na}$ ótica neoliberal a produção e a socialização de conhecimentos acabam gerando gastos sociais, em que o Estado acaba disseminando o discurso de minimizar a esfera social para a retomada da economia, isto é, diminuir o campo social para aumentar a rotação do capital. Dessa maneira, o Estado se apropria do argumento de ineficiência e insustentabilidade para ampliar as concepções e estratégias ofensivas neoliberais que são regressivas para garantia e defesa dos direitos sociais, políticos e econômicos. 
Essas concepções de restrições orçamentárias por parte do Estado, ao fim e ao cabo, revelam a dimensão transformadora que o conhecimento contém para possibilitar aos sujeitos de modo coletivo de enfrentarem o debate crítico, como também de construir e intervir nos aspectos sociais, políticos e econômicos, procurando superar as contradições entre as classes, por meio da busca por uma nova ordem societária emancipadora.

\section{Considerações Finais}

A dimensão investigativa relaciona-se com a construção e produção do conhecimento que poderá possibilitar a liberdade de ideologias ou visões de mundo conservadores, como também a busca de alternativa que viabilize a transformação da realidade social desde que comprometida com a desnaturalização da estrutura desigual da sociedade contemporânea.

\section{[...] podemos compreender que}

a pesquisa no âmbito das

relações do Serviço Social não

está voltada apenas para a

descrição ou reflexão em si do

mundo real, mas se constitui

uma atividade transformadora,

a qual tem o objetivo de

construir os diversos

conhecimentos sobre as

múltiplas expressões da

Questão Social por meio da

aproximação, explicação e

apreensão dos aspectos sociais,

econômicos, políticos e cultuais

da realidade social, buscando

encontrar respostas diante os

desafios que são postos para a

sociedade em geral.

Dessa maneira, é importante destacar que não existe um saber absoluto, isto é, algo pronto e acabado. Posto isto, a pesquisa consiste em um espaço aberto para o coletivo para desvendar, questionar, refletir e apreender o movimento dialético entre os sujeitos e a sua formação social. A partir disso, é no campo da pesquisa que temos a elaboração de ideias ou concepções, bem como a escolha do conjunto de métodos, técnicas e procedimentos adequados para o entendimento do mundo real.

A dimensão investigativa no Serviço Social tem contribuído para a transformação da realidade de seus usuários, através da defesa dos direitos sociais buscando eliminar todas as formas de opressão, exploração, preconceito ou discriminação social, procurando fortalecer e ampliar a concepção de sociedade democrática e igualitária, por meio da produção de conhecimentos, o qual possui um papel social, político e científico fundamental para proporcionar uma boa qualidade nos serviços e atendimentos sociais à população.

Nesse sentido, podemos enfatizar a área do Serviço Social no âmbito da investigação, o qual constitui uma práxis transformadora e imprescindível, seja na esfera acadêmica ou na atuação do exercício profissional, vinculado nas diretrizes curriculares e no projeto profissional que visa à interlocução da teoria crítica, competência técnica e o compromisso ético e político.

Acerca dos desafios para a pesquisa na formação acadêmica e profissional, especificamente no campo do Serviço Social é interessante realizar a crítica ao produtivismo, isto é, ausência do compromisso e aprofundamento do conhecimento crítico. Outra dificuldade para a formação profissional qualificada e para o âmbito da pesquisa na área de Serviço Social é o avanço e pulverização dos cursos a distância que vêm crescendo sem ter comprometimento algum com a formação de qualidade, bem como não leva em consideração o tripé ensino-pesquisa-extensão, que consideramos imprescindível para uma formação crítica e de qualidade, e que afrontam diretamente as diretrizes curriculares do curso supracitado. A expansão do ensino aligeirado, o qual tem se alinhado às exigências do mercado, desconsidera o ensino, pesquisa e extensão ocasionando a reprodução de sujeitos operacionais que aceitam os discursos naturalizantes, alienantes e conservadores da elite burguesa, sem a incorporação da perspectiva da práxis transformadora, o que se constitui um desafio para a ampliação da dimensão investigativa.

Em decorrência disso, temos a desestruturação da política de educação, no que se refere à redução de recursos orçamentários, o que tem contribuído para a fragmentação da construção crítica do conhecimento na formação acadêmica e profissional, sendo necessário a luta e o enfrentamento da cultura dominante, cultura 
essa, vinculada ao modelo capitalista que apenas prioriza a elevação e obtenção da lucratividade. Por isso, se faz necessário o fortalecimento da atividade científica da pesquisa, tendo a centralidade o ensino, pesquisa e extensão pra proporcionar a formulação de possibilidades ou alternativas interventivas.

Diante dos diversos limites postos pela conjuntura neoliberal, as(os) assistentes sociais utilizam a pesquisa como prática profissional fundamental para compreender e intervir na realidade concreta, ir além das aparências ou imediaticidades dos fatos, sempre procurando realizar as articulações devidas entre a esfera do particular e da totalidade das demandas para chegar à essência das coisas.

Portanto, é salutar reafirmar que a pesquisa científica no Serviço Social contribui para o alargamento do saber e para a atuação qualificada da categoria profissional no que tange ao enfrentamento das mais variadas expressões da Questão Social, a fim de viabilizar a mobilização da luta e defesa intransigente dos direitos compromissada com a qualidade dos bens e serviços prestados à população, bem como para a ruptura e superação de análises discriminatórias e a construção de uma sociedade humanamente emancipada.

\section{Referências}

BAPTISTA, Myrian Veras. A investigação em Serviço Social. São Paulo: Veras; Lisboa, [Portugal]: Centro Português de Investigação em História e Trabalho Social (CPIHIS), 2006. p. 15-34.

DEMO, Pedro. Introdução ao ensino da metodologia da ciência. 2. ed. São Paulo: Atlas, 1987.

FAZENDA, Ivani Catarina Arantes. Interdisciplinaridade: história, teoria e pesquisa. 15. ed. Campinas, SP: Papirus, 2008.

FERRAREZ, Cynthia Santos. Mercantilização da educação superior brasileira e a formação profissional do serviço social. Temporalis, Brasília, DF, ano 16, n. 31, jan./jun. 2016. Disponível em: http://periodicos.ufes.br/temporalis/article/view/12243/10099. Acesso em: 17 jun. 2019.

FERREIRA, Catyelle Maria de Arruda et al. A importância da pesquisa para o curso de serviço social: perspectiva histórica e atual. In: ENCONTRO LATINO AMERICANO DE INICIAÇÃO CIENTÍFICA, 13., e ENCONTRO LATINO AMERICANO DE PÓSGRADUAÇÃO, 9., São José dos Campos, 2009. Anais [...]. Universidade do Vale da Paraíba, 2009.

GODOY, Arilda Schmidt. Introdução à pesquisa qualitativa e suas possibilidades. Revista de Administração de Empresas, São Paulo, v. 35, n. 2, p. 57-63, 1995.

GUERRA; Yolanda; BACKX, Sheila; REPETTI, Gustavo. O lugar da pesquisa na formação profissional: algumas questões a partir dos relatórios das regionais da ABEPSS. Temporalis, Brasília, ano 13, n. 25, p. 205-232, jan./jun. 2013.

IAMAMOTO, Marilda Villela. Serviço Social em tempo de capital fetiche: capital financeiro, trabalho e questão social. São Paulo: Cortez, 2007.

JOHNSON, A. G. Dicionário de Sociologia: guia prático da linguagem. Rio de Janeiro: Jorge Zahar, 1997. p. 82-83.

KOIKE, Maria Marieta. Formação Profissional em Serviço Social: exigências atuais. In: CONSELHO FEDERAL DE SERVIÇO SOCIAL (CFESS). Serviço Social: Direitos Sociais e Competências Profissionais. v.1. Brasília, 2009.

LAVILLE, Christian; DIONNE, Jean. A construção do saber: manual de metodologia da pesquisa em ciências humanas. Tradução: Heloisa Monteiro e Francisco Settineri. Porto Alegre: Artmed; Belo Horizonte: Editora da UFMG, 1999.

MORAES, Carlos Antônio de Souza. A "viagem de volta”: significados da pesquisa na formação e prática profissional do Assistente Social. Serviço Social \& Sociedade, São Paulo, n. 114, p. 240-265, abr.jun. 2013.

MORAES, Carlos Antônio de Souza; JUNCÁ, Denise Chrysóstomo de Moura; SANTOS, Katarine de Sá. Para quê, para quem, como? Alguns desafios do cotidiano da pesquisa em serviço social. Serviço Social \& Sociedade, São Paulo, n. 103, p. 433-452, jul./set. 2010. Disponível: http://www.scielo.br/pdf/sssoc/n103/a03n103.pdf. Acesso em: 24 jun. 2019.

PEREIRA, Potyara A. P. A utilidade da pesquisa para o serviço social. Serviço Social e Saúde, Campinas, v. 4, p. 1-158, maio 2005. REIS, Ana Beatriz Oliveira. O objeto de pesquisa em ciências sociais: para além da contemplação. In: BELLO, Enzo; ENGELMANN, Wilson. (coord.). Metodologia da pesquisa em direito [recurso eletrônico]. Caxias do Sul, RS: Educs, 2015. p. 154-164.

SETUBAL, Aglair Alencar. Desafios à pesquisa no Serviço Social: da formação acadêmica à prática profissional. Katálysis, Florianópolis, v. 1, núm. esp., p. 4-72, 2007. Disponível em: http://www.scielo.br/scielo.php?pid=S1414-49802007000300007\&script=sci Abstract\&tlng=pt. Acesso em: 15 jun. 2019.

SILVA, Alessandra Ximenes da; MATIAS, Thaísa Simplicio Carneiro; NÓBREGA, Mônica, Barros da. Pesquisa e conhecimento da realidade. Temporalis, Brasília, DF, ano 18, n. 3, jan./jun. 2018. Disponível em: http://periodicos.ufes.br/temporalis/article/view/19755/ pdf. Acesso em: 10 jun. 2019.

\section{Nota}

1 Segundo Koike (2009), o projeto pedagógico pensando e consolidado nos anos de 1990, após o intenso processo de debates e reflexões acerca do Serviço Social no Brasil “ "iniciado com o Movimento de Reconceituação e que possui no III Congresso Brasileiro de Assistentes Sociais (CBAS) 
o seu marco histórico e político - comunga com o projeto ético político fruto da maturação intelectual das(os) profissionais e que vai nortear a categoria, política e ideologicamente, na viabilização dos direitos sociais.

\section{Luciene Araújo}

assistente.luciene@gmail.com

Graduação em Serviço Social pela Universidade do Estado do Rio Grande do Norte (UERN)

Mestranda do Programa de Pós-Graduação em Serviço Social e Direitos Sociais (UERN)

\section{Gilcélia Batista de Góis}

gilceliagois@gmail.com

Doutorado em Ciências Sociais pela Universidade Federal do Rio Grande do Norte (UFRN)

Professora adjunta IV da graduação em Serviço Social e do Programa de Pós-Graduação em Serviço Social e Direitos Sociais (UERN)

\section{Gleidiane Almeida de Freitas}

gleidianealmeidaass@gmail.com

Graduação em Serviço Social pela Universidade do Estado do Rio Grande do Norte (UERN)

Integrante do Núcleo de Estudos e Pesquisas sobre a Terceira Idade (NEPTI)

\section{Mariana Gleicy de Oliveira Silva Sousa}

mariana.gleicy@hotmail.com

Graduação em Serviço Social pela Universidade do Estado do Rio Grande do Norte (UERN)

Integrante do Núcleo de Estudos e Pesquisas sobre a Terceira Idade (NEPTI)

\section{UERN}

Rua Professor Antônio Campos, s/n, BR 110, Km 48, Costa e Silva

Mossoró - Rio Grande do Norte - Brasil

CEP: $59.600-000$

\section{Agradecimentos \\ Não se aplica. \\ Agência financiadora \\ Não se aplica.}

\section{Contribuições das autoras}

$\mathrm{O}$ artigo foi construído de forma conjunta possibilitando a contribuição de todas as autoras no decorrer do texto.
Aprovação por Comitê de Ética e consentimento para participação

Não se aplica.

Consentimento para publicação

Não se aplica.

Conflito de interesses

Não há conflito de interesses. 